Chapter 6

\title{
UWB Antennas for Wireless Applications
}

\author{
Osama Haraz and Abdel-Razik Sebak \\ Additional information is available at the end of the chapter \\ http://dx.doi.org/10.5772/51403
}

\section{Introduction}

Currently, there is an increased interest in ultra-wideband (UWB) technology for use in several present and future applications. UWB technology received a major boost especially in 2002 since the US Federal Communication Commission (FCC) permitted the authorization of using the unlicensed frequency band starting from 3.1 to $10.6 \mathrm{GHz}$ for commercial communication applications [1]. Although existing third-generation (3G) communication technology can provide us with many wide services such as fast internet access, video telephony, enhanced video/music download as well as digital voice services, UWB -as a new technology- is very promising for many reasons. The FCC allocated an absolute bandwidth up to $7.5 \mathrm{GHz}$ which is about $110 \%$ fractional bandwidth of the center frequency. This large bandwidth spectrum is available for high data rate communi-cations as well as radar and safety applications to operate in. The UWB technology has another advantage from the power consumption point of view. Due to spreading the ener-gy of the UWB signals over a large frequency band, the maximum power available to the antenna -as part of UWB system- will be as small as in order of $0.5 \mathrm{~mW}$ according to the FCC spectral mask. This power is considered to be a small value and it is actually very close to the noise floor compared to what is currently used in different radio communica-tion systems [2].

\subsection{Different UWB Antenna Designs}

UWB antennas, key components of the UWB system, have received attention and significant research in recent years [3]-[28]. With theincreasing popularity of UWB systems, there have been breakthroughs in the design of UWB antennas. Implementation of a UWB system is facing many challenges and one of these challenges is to develop an appropriate antenna. This is because the antenna is an important part of the UWB system and it affects the overall performance of the system. Currently, there are many antenna designs that can achieve 
broad bandwidth to be used in UWB systems such as the Vivaldi antenna, bi-conical antenna, $\log$ periodic antenna and spiral antenna as shown in Fig. 1. A Vivaldi antenna [3]-[4] is one of the candidate antennas for UWB operation. It has a directional radiation pattern and hence it is not suitable for either indoor wireless communication or mobile/portable devices which need omni-directional radiation patternsto enable easyand efficient communication between transmitters and receivers in all directions. Mono-conical and bi-conical antennas [5] have bulky structures with large physical dimensions which limit their applications. Also, log periodic [6] and spiral antennas [7] are two different UWB antennas that can operate in the 3.1-10.6 GHz frequency band but are not recommended for indoor wireless communicationapplications or mobile/portable devices. This is because they have large physical dimensions as well as dispersive characteristics with frequency and severe ringing effect [6]. This is why we are looking for another candidate for UWB indoor wireless communications and mobile/portable devices that can overcome all these shortcomings. This candidate is the planar or printed monopole antenna [8]-[28]. Planar monopole antennas [8]-[10] with different shapes of polygonal (rectangular, trapezoidal...etc), circular, elliptical...etc have been proposed for UWB applications as shown in Fig. 2.

\subsection{UWB Antennas for Wireless Communications}

Due to their wide frequency impedance bandwidth, simple structure, easy fabrication on printed circuit boards (PCBs), and omni-directional radiation patterns, printed PCB versions of planar monopole antennas are considered to be promising candidates for applications in UWB communications. Recent UWB antenna designs focus on small printed antennas because of their ease of fabrication and their ability to be integrated with other components on the same PCBs [11]-[19]. Fig. 3 illustrates several realizations of planar PCB or printed antenna deigns.

\subsection{UWB Antennas with Bandstop Function}

However, there are several existing NB communication systems operating below $10.6 \mathrm{GHz}$ in the same UWB frequency band and may cause interference with the UWB systems such as IEEE 802.11a WLAN system or HIPERLAN/2 wireless system. These systems operate at 5.15-5.825 GHz which may cause interference with a UWB system. To avoid the interference with the existing wireless systems, a filter with bandstop characteristics maybe integrated with UWB antennas to achieve a notch function at the interfering frequency band [21]-[28]. Fig. 4 shows several developed bandstop antenna designs.

This chapter focuses on the development of different novel UWB microstrip-line-fed printed disc monopole and hybrid antennas with an emphasis of their frequency domain performance. Different antenna configurations are proposed and designed in order to find a good candidate for UWB operation. The reasonable antenna candidate should satisfy UWB performance requirements including small size, constant gain, radiation pattern stability and phase linearity through the frequency band of interest. Also, the designed UWB antenna should have ease of manufacturing and integration with other mi-crowave components. We have simulated, designed, fabricated and then tested experi-mentally different printed disc 
monopole antenna prototypes for UWB short-range wireless communication applications. The printed disc monopole antennas are chosen because they have small a size and omnidirectional radiation patterns with large bandwidth. In order to understand their operation mechanism that leads to the UWB characteristics, those antenna designs are numerically studied. Also, the important physical parameters which affect the antenna performances are investigated numerically using extensive parametric studies in order to obtain some quantitative guidelines for designing these types of antennas.

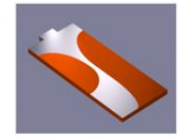

(a)

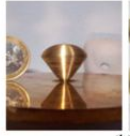

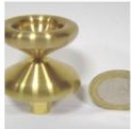

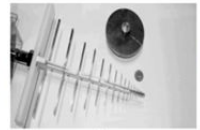

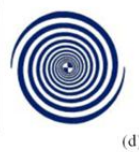

(d)

Figure 1. (a) Vivaldi antenna [4] (b) Mono-conical and bi-conical antenna [5] (c) Log-periodic antenna [6] and (d) Spiral and conical spiral antenna [7].

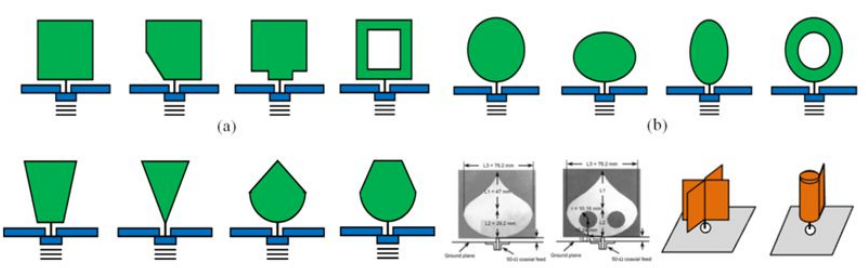

(c)

Figure 2. Modified shape planar antennas for UWB applications (a) rectangular, (b) circular and elliptical, (c) other shapes.
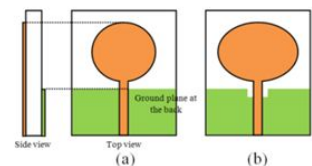

(b)

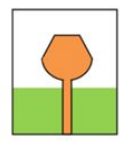

(c)

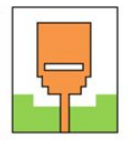

(d)

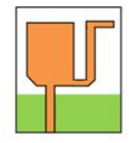

(e)

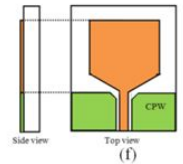

(i)

Figure 3. Planar PCB or printed antenna designs [8]-[20].
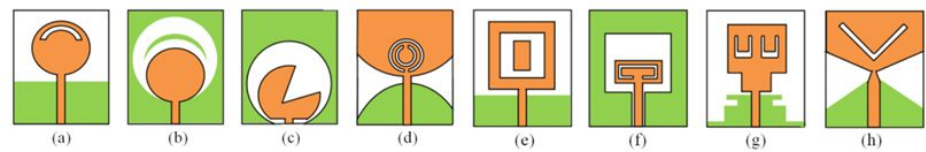

Figure 4. Printed antenna designs with single bandstop functions [21]-[28]. 


\section{Operation Mechanism of UWB Monopole Antennas}

Printed disc monopole antennas are considered to be good candidates for UWB applications because they have a simple structure, easy fabrication, wideband characteristics, and omnidirectional radiation patterns [11]-[28]. The geometry of the reference printed circular disc monopole antenna is shown in Fig. 5. To determine the initial parameters of the printed circular disc monopole antenna, we should first understand their operation mechanism. It has been shown that disc monopoles with a finite ground plane are capable of supporting multiple resonant modes instead of only one resonant mode (as in a conventional circular patch antenna) over a complete ground plane [29]. Overlapping closely spaced multiple resonance modes (f1, f2, f3, ..., fN) as shown in Fig. 6 can achieve a wide bandwidth and this is the idea behind the UWB bandwidth of circular disc monopole antennas. The frequency of the first resonant mode can be determined by the size of the circular disc. At the first resonance f1, the disc antenna tends to behave like a quarter-wavelength monopole antenna, i.e. $\lambda / 4$. That means the diameter of the circular disc is $2 r=\lambda / 4$ at the first resonant frequency.

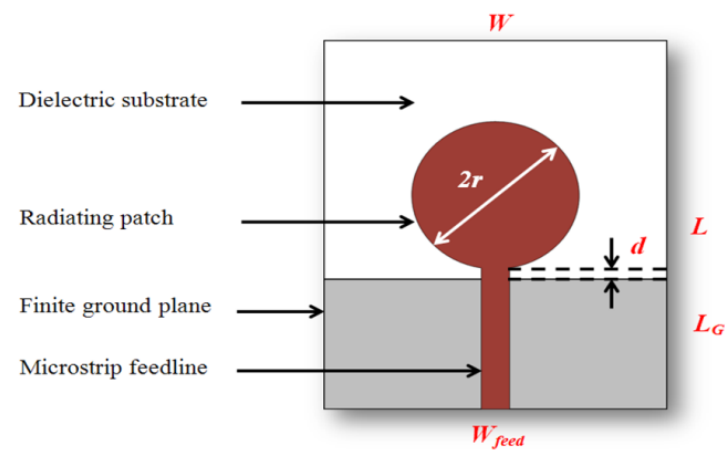

Figure 5. The configuration of the reference printed circular disc monopole antenna showing the necessary antenna parameters.

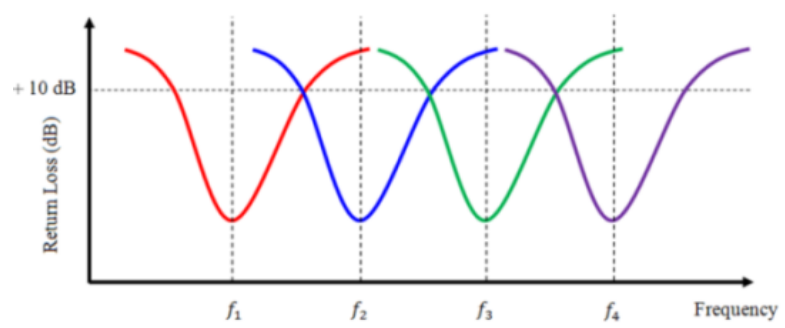

Figure 6. The concept of overlapping closely-spaced multiple resonance modes for the reference circular disc monopole antenna (reproduced from [30]). 
Then the higher order modes $\mathrm{f} 2, \mathrm{f} 3, \ldots, \mathrm{fN}$ will be the harmonics of the first or fundamental mode of the disc. Unlike the conventional patch antennas with a complete ground plane, the ground plane of disc monopole antennas should be of a finite length LG to support multiple resonances and hence achieve wideband operation. The width of the ground plane $W$ is found to be approximately twice the diameter of the disc or $W=\lambda / 2$ at the first resonant [17].

The printed disc monopole antenna can be fed using different feeding techniques such as microstrip line, coplanar waveguide $(\mathrm{CPW})$, aperture coupling, or proximity coupling. In the case of a microstrip line feed, the width of the microstrip feed line Wfeed is chosen to achieve a $50 \Omega$ characteristic impedance. The other antenna parameters such as the feed gap between the finite ground plane and the radiating circular disc $d$ and the length of the finite ground plane LG can be determined using a full-wave EM numerical modeling techniques. The small feed gap between the finite ground plane and the radiating circular disc $\mathrm{d}$ is a very critical parameter which greatly affects the antenna impedance matching between the microstrip feedline and the radiating disc.

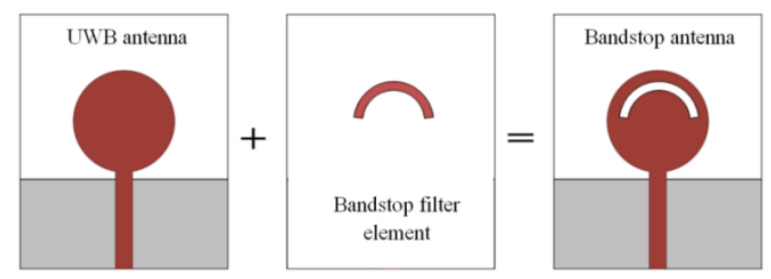

Figure 7. The idea of integrating a bandstop filtering element to the reference circular disc monopole antenna.

To avoid interference with some existing wireless systems in the 5.15-5.825 GHz frequency band, a filter with bandstop characteristics maybe integrated with UWB antennas to achieve a notch function at the interfering frequency band. The idea of integrating a bandstop filtering element to the monopole antenna is illustrated in Fig. 7. Recently, several techniques have been introduced to achieve a single band notch within this frequency band. The most popular technique is embedding a narrow slot into the radiating patch. The slot may have different shapes such as C- shaped, slit ring resonator (SRR), L- shaped,U- or V- shaped, $\pi$ shaped slot....etc. Some other techniques are based on using parasitic strips, i.e., inverted Cshaped parasitic strip. Other techniques are based on using a slot defected ground structure in the ground plane, i.e., H-shaped slot DGS.

\section{UWB Disc Monopole Antennas}

As mentioned in the introductory section of this chapter, there are several types of printed disc monopoles which exhibit ultra-wide impedance bandwidth. Here, different categories of disc monopoles will be investigated both numerically and experimentally. 


\subsection{Printed Circular Disc Monopole Antenna with Two Steps and a Circular Slot}

For better understanding the antenna characteristics, the antenna reflection coefficient (S11) curves are plotted in decibel or $\mathrm{dB}$ scale, i.e. $(\mathrm{S} 11 \mathrm{~dB}=20 \log |\mathrm{S} 11|=-$ Return loss RL).The geometry and photograph of the proposed printed circular disc monopole antenna with two steps and a circular slot is shown in Fig. 8. The radiating element is fed by a $50 \Omega$ microstrip feed line with width of $\mathrm{Wf}=4.4 \mathrm{~mm}$. The substrate used in our design is Rogers RT/duroid 5880 high frequency laminate with thickness of $\mathrm{h}=1.575 \mathrm{~mm}$, relative permittivity of $\varepsilon \mathrm{r}=2.2$ and loss tangent of tan $\delta=0.0009$. A finite ground plane of length LG and width $W$ lies on the other side of the substrate. The feed gap of width $d$ between the finite ground plane and the radiating patch is a very critical parameter for antenna matching purposes and to obtain wide bandwidth performance. This proposed antenna has a reduction in the overall antenna surface area compared to those reported in [16] and [19]. A parametric study is carried out to investigate the effect of antenna physical parameters such as the width of the substrate $\mathrm{W}$, the width of the feed gap $d$, the radius of circular slot RS and the steps dimensions W1, W2, L1 and L2 on the performance of the proposed UWB antenna.

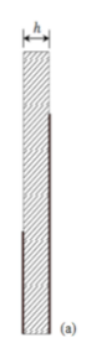

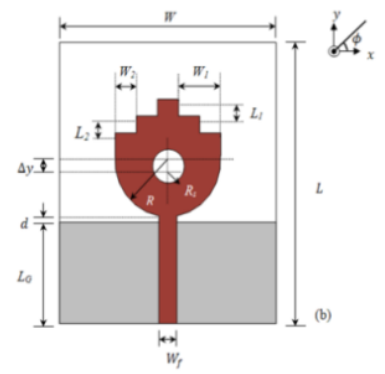

(a)

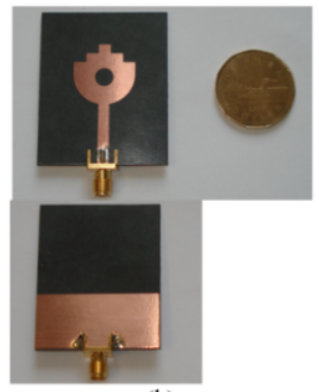

(b)

Figure 8. (a) Geometry and (b) photograph of the proposed microstrip line fed monopole antenna.

\subsubsection{Design Analysis}

During the parametric study, one parameter varies while all other parameters are kept fixed. The optimized antenna parameters are: $\mathrm{W}=41 \mathrm{~mm}, \mathrm{~L}=50 \mathrm{~mm}, \mathrm{LG}=18 \mathrm{~mm}, \mathrm{R}=10 \mathrm{~mm}, \Delta \mathrm{y}$ $=2 \mathrm{~mm}, \mathrm{RS}=3 \mathrm{~mm}, \mathrm{~W} 1=8 \mathrm{~mm}, \mathrm{~W} 2=4 \mathrm{~mm}, \mathrm{~L} 1=3 \mathrm{~mm}$ and L2 $=3 \mathrm{~mm}$. Fig. 9 shows the simulated antenna reflection coefficient $(20 \log |\mathrm{S} 11|)$ curves using CST Microwave Studio TM package for different values of substrate width $W$, feed gap width $d$, slot radius $R S$ and the steps dimensions W1, W2, L1 and L2. It can be noticed from results that the smallest substrate width for obtaining the maximum available bandwidth is $\mathrm{W}=41 \mathrm{~mm}$. It can be also seen that the reflection coefficient impedance bandwidth is greatly dependent on both the feed gap width $\mathrm{d}$ and the circular slot radius RS and by controlling these two parameters, the impedance matching between the radiating patch and the feed line can be easily controlled. By tuning the width of the feed gap $d$, the maximum achieved impedance bandwidth is 
determined. The circular slot inside the radiating patch acts as an impedance matching element which controls the antenna impedance matching as well as the antenna bandwidth. Also, the circular slot inside the radiating patch can be used for miniaturizing the monopole antenna. Also, it can be noticed that the rectangular steps have no remarkable effect on the overall antenna impedance bandwidth. The opti-mum values for feed gap width, slot radius and steps dimensions are $\mathrm{d}=1 \mathrm{~mm}, \mathrm{RS}=3 \mathrm{~mm}$ and $\mathrm{W} 1(=2 \mathrm{~W} 2)=8 \mathrm{~mm}$ and $\mathrm{L} 1(=\mathrm{L} 2)=3$ $\mathrm{mm}$, respectively.

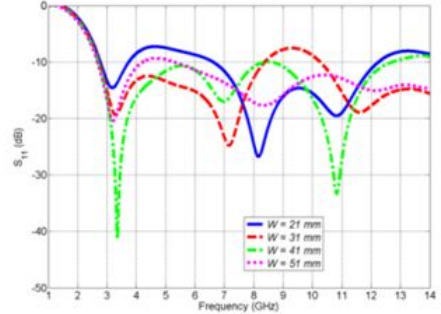

(a)

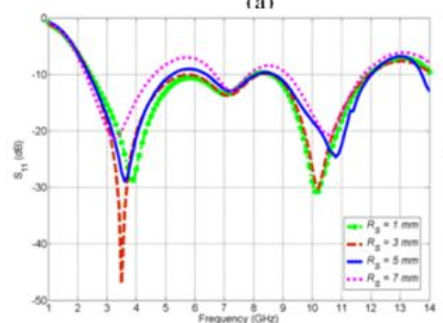

(c)

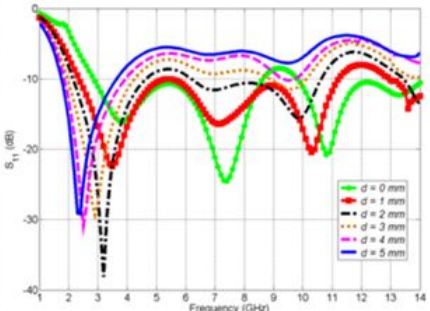

(b)

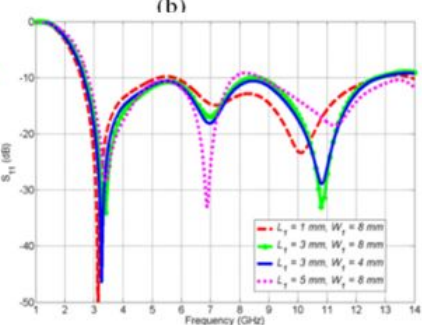

(d)

Figure 9. Parametric studies of effect of (a) substrate width W (b) feed gap width d (c) circular slot radius RS and (d) steps dimensions $\mathrm{W} 1$ and $\mathrm{L} 1$ on antenna reflection coefficient.

Cutting out two rectangular steps and a circular slot from the radiating patch to reduce the overall metallic area and hence reduce the antenna copper losses without affecting the antenna operation or disturbing the current distribution of the antenna is a challenging task. This can be done by investigating the antenna surface current distributions. Fig. 9 presents the antenna surface current and electric field distributions for the proposed disc monopole antenna. From the electric field distributions, it is noticed that the monopole antenna supports multiple resonant modes. It can be seen that the current distribution is mainly located close to the radiating patch edges rather than in the center. For increasing the maximum achieved impedance bandwidth, the lower resonant frequency should be decreased. This can be done by increasing the antenna perimeter which directly affects lower resonant frequency and then the antenna impedance bandwidth. To increase the antenna perimeter, cutting out steps from the radiating patch are used here. This is simply because the surface current will take longer path when the antenna perimeter $\mathrm{p}$ is larger and the new antenna 
with larger perimeter appears to be like a longer length monopole and then the lowest resonance frequency fL will be decreased according to [14]:

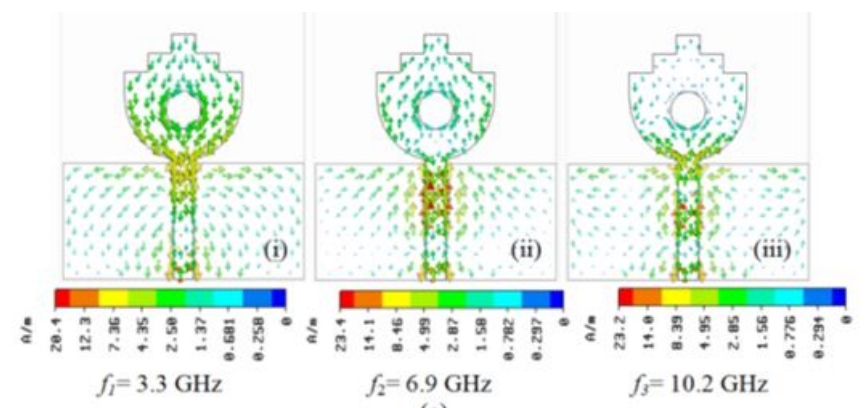

(a)

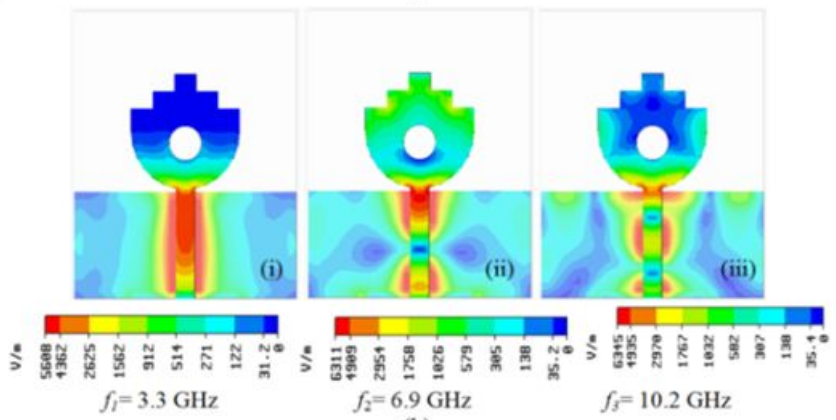

(b)

Figure 10. Simulated (a) surface current and (b) electric field distributions at the three re-sonant frequencies $3.3,6.9$ and $10.2 \mathrm{GHz}$.

$$
\begin{gathered}
\varepsilon_{\text {eff }} \approx\left(\varepsilon_{r}+1\right) / 2 \\
f_{L}(\mathrm{GHz})=300 /\left(p \sqrt{\varepsilon_{e f f}}\right)
\end{gathered}
$$

where $\varepsilon$ eff is the effective dielectric constant and the perimeter $\mathrm{p}$ units are in millimeters.

For example, in the proposed antenna design, $\mathrm{p}=71.4 \mathrm{~mm}, \varepsilon \mathrm{r}=2.2$, then $\varepsilon$ eff $=1.6$ and the calculated lower resonant frequency using Eq. (2) is found to be $\mathrm{fL} \approx 3.3 \mathrm{GHz}$. From the simulated and measured reflection coefficient results shown in Fig. 10, the lower resonant frequency is $\mathrm{fL} \approx 3.3 \mathrm{GHz}$ which agrees well with the calculated value.

\subsubsection{Experimental and Simulation Results}

A prototype of the microstrip-line-fed monopole antenna with optimized dimensions was fabricated as shown in Figure8and tested experimentally in the Applied Electromagnetics 
Laboratory at Concordia University. All scattering parameters measurements were carried out using Agilent E8364B programmable network analyzer (PNA). The measured and simulated reflection coefficient (S11) curves are presented in Fig. 11. It can be noticed that both measured and simulated results are in good agreement with each other and the measured 10 $\mathrm{dB}$ return loss bandwidth ranges from 3.0 to $11.4 \mathrm{GHz}$ which covers the entire UWB frequency spectrum. Compared to the simulated results, the second resonant frequency at 7 $\mathrm{GHz}$ is shifted up while the third resonant frequency at $10 \mathrm{GHz}$ is shifted down. This may be due to the sub-miniature version A (SMA) connector losses and/or substrate losses especially at high frequencies $(7-10 \mathrm{GHz})$. Even the loss effect of the substrate is modeled correctly and taken into account in the simulations; the simulation results did not change too much and did not agree with the measured results. In general, the proposed antenna exhibits an UWB impedance bandwidth (3.1-10.6 GHz) in both simulated and measured results.

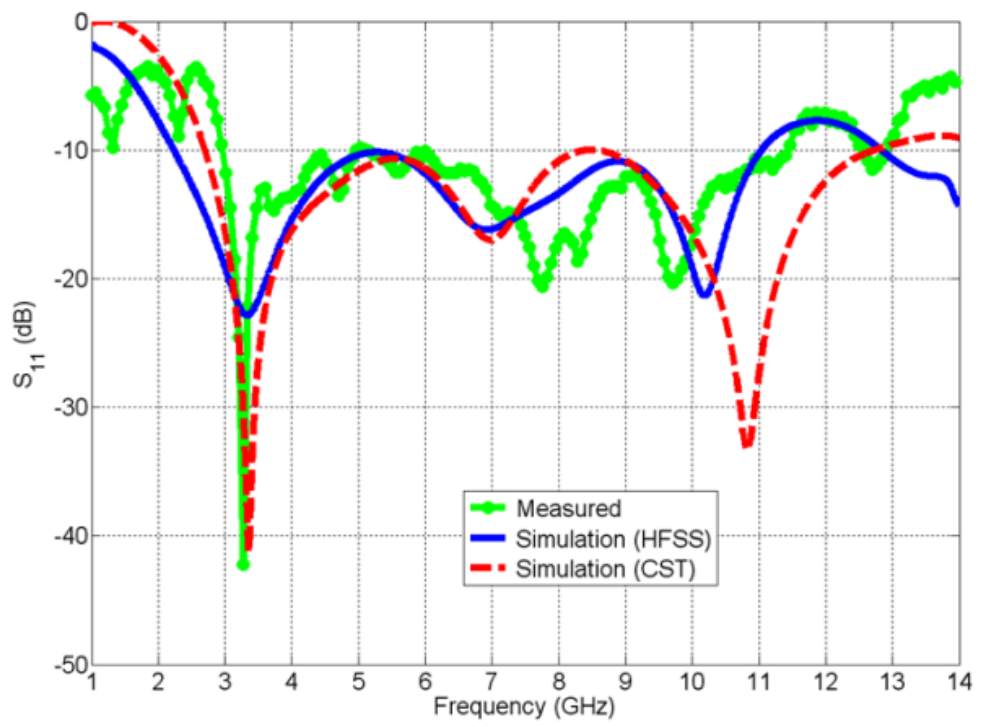

Figure 11. Measured and simulated reflection coefficient curves of the proposed antenna.

For further understanding the antenna performance, the Ansoft HFSS simulated maximum realized total directive gain in the boresight direction and the phase of reflection coefficient $\angle \mathrm{S} 11$ for the proposed antenna are presented in Fig. 12. The boresight of directional antenna is defined as the direction of maximum gain of the antenna. For most of antennas, the boresight is the axis of symmetry of the antenna, i.e. z-axis. It can be seen that the antenna has good gain stability across the frequency band of interest (3.1-10.6 GHz).It ranges from $3.4 \mathrm{~dB}$ to $5.2 \mathrm{~dB}$ with gain variation of about $2 \mathrm{~dB}$. The behavior of the phase of reflection coefficient $\angle \mathrm{S} 11$ versus frequency is also studied and shown in the same figure. It can be noticed that the phase seems to be linear across the whole UWB frequency range. 


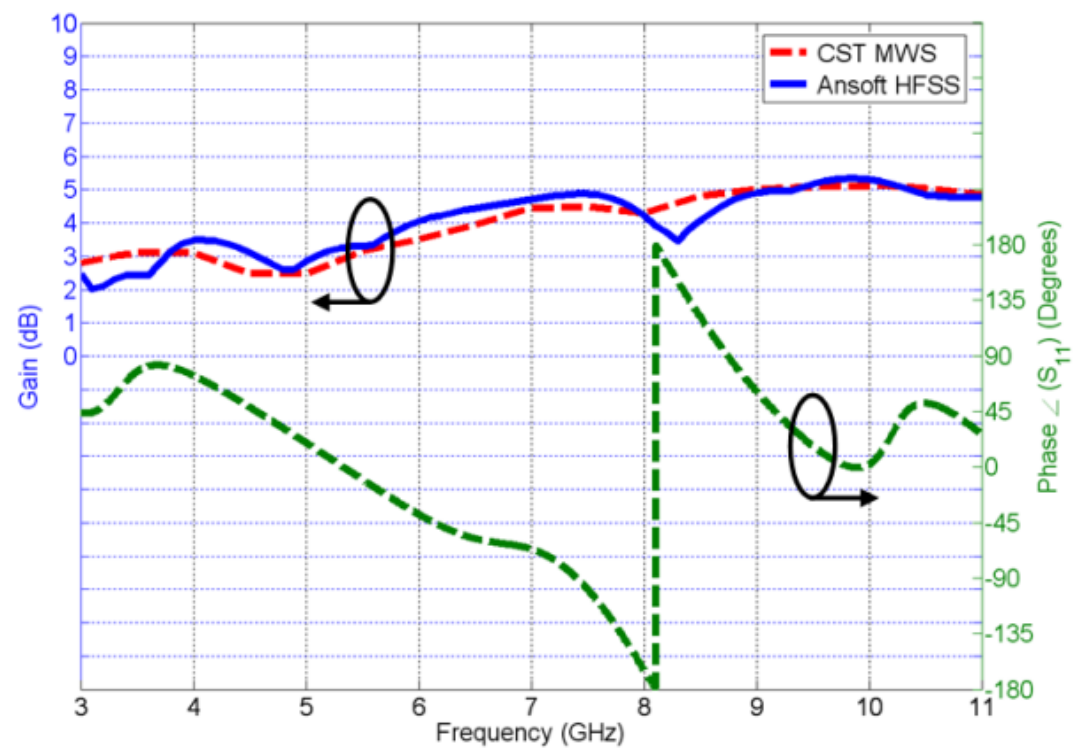

Figure 12. The simulated gain and phase of reflection coefficient $\angle \mathrm{S} 11$ versus frequency of the proposed microstripline-fed monopole antenna.

Fig. 13 shows the radiation characteristics for the proposed antenna. Both yz-cut plane (Eplane) and xz-cut plane (H-plane) radiation patterns have been simulated using Ansoft HFSS and measured in an anechoic chamber at the three resonant frequen-cies 3.3, 6.8, and 10.2 GHz. From the measured results, the proposed antenna has omni-directional radiation pattern in H-plane at lower frequency $(3.3 \mathrm{GHz})$ and near omni-directional at higher frequencies (6.9 and $10.2 \mathrm{GHz}$ ) with good agreement with simula-tions. The measured E-plane radiation patterns agree with the simulations especially at lower frequency $(3.3 \mathrm{GHz})$ while the agreement is not as good as the H-plane patterns at higher frequencies (6.9 and 10.2 $\mathrm{GHz}$ ). There are some ripples and discrepancies in the measured radiation patterns especially at the higher frequencies which may be due to sen-sitivity and accuracy of the measuring devices at higher frequencies in addition to the ef-fects of the SMA feed connector and the coaxial cable. The E-plane is identified by most of UWB antenna patterns which is perpendicular to H-plane (almost symmetric). Re-searchers in UWB antenna typically define Eplane as the plane containing the feedline and the maximum radiation of the antenna. $\mathrm{H}$ plane is the plane perpendicular to E-plane.

We have investigated both simulated and measured E-plane patterns. From simu-lations, nulls in E-plane at $\theta=90^{\circ}$ depend on the size of the finite ground plane and the contact point of SMA feed connector in particular at the upper edge frequency. By searching several published UWB antennas of similar disc monopole antennas, similar behavior of measured results are reported in many papers including [31]-[34]. 

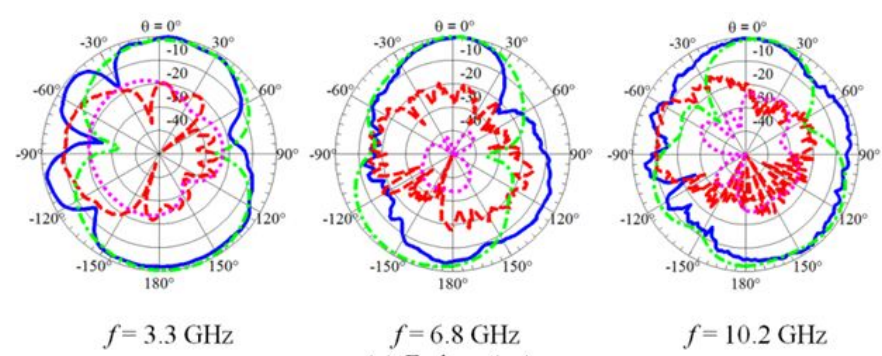

$f=6.8 \mathrm{GHz}$

(a) E-plane (yz)

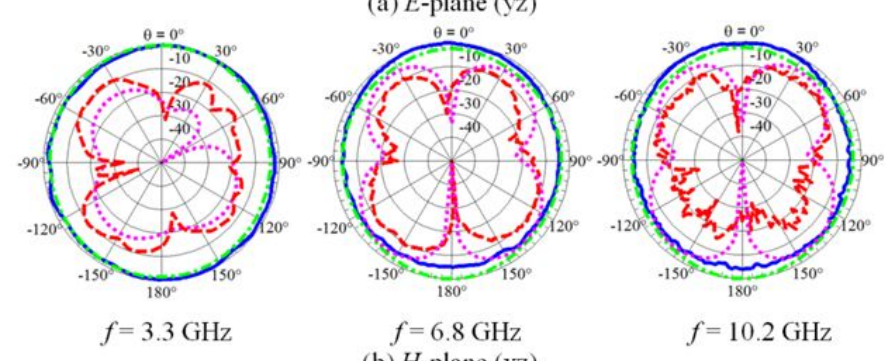

(b) $H$-plane (xz)

Figure 13. Measured co-pol (blue solid line), cross-pol (red dashed line), Ansoft HFSS simulated co-pol (green dashdotted line) and cross-pol (magenta dotted line), (a) E-plane and (b) $\mathrm{H}$-plane radiation patterns of the proposed antenna.

\subsubsection{UWB Bandstop Antenna Design}

A modification can be made to the above designed antenna for achieving the bandstop function to avoid possible interference to other existing WLAN systems. A very narrow arcshaped slot is cut away from the radiating patch as shown in Fig. 14 (a) will act as a filter element to make the antenna will not respond at the bandstop frequency. For perfect bandrejection performance of UWB antenna, the return loss of the stop-band notch should be almost $0 \mathrm{~dB}$ or the reflection coefficient is almost 1.0. However, in our first band-stop antenna design, we could achieve voltage standing wave ratio (VSWR) of about 8 (reflection coefficient is 0.78 or $-2.1 \mathrm{~dB}$ ). The arc-shaped slot filter element di-mensions will control both the bandstop frequency fnotch and the rejection bandwidth of the band-notched filter BWnotch. The arc-shaped slot filter dimensions are: the radius of the slot R1, the thickness of the slot $\mathrm{T}$ and the slot angle $2 \alpha$. Fig. 14 (b) illustrates the simulated reflection coefficient curves using both HFSS and CST MWS for comparison. From the simulation results, it can be seen that the band-notched characteristic in the 5.0-6.0 GHz band is achieved with good agreement between them.

Parametric studies were carried out to address the effect of arc-shaped slot dimen-sions on the band-notched performance. Figures 15 shows the effect of varying the slot radius R1, slot thickness $\mathrm{T}$ and the slot angle $2 \alpha$ parameters on the simulated antenna ref-lection coefficient, respectively. From results in Fig. 15 (a) \& (c), it can be seen that the notch frequency fnotch 
decreases by increasing both the arc-shaped slot radius R1 and the angle $2 \alpha$ while the notch bandwidth BWnotch is almost the same. On the other side, both the notch frequency and bandwidth increase at the same time by increasing the slot thickness T. For achieving a band-notched performance in the 5-6 GHz frequency band, the arc-shaped slot parameter dimensions are: $\mathrm{R} 1=7.5 \mathrm{~mm}, \mathrm{~T}=0.7 \mathrm{~mm}$ and $2 \alpha=160^{\circ}$.

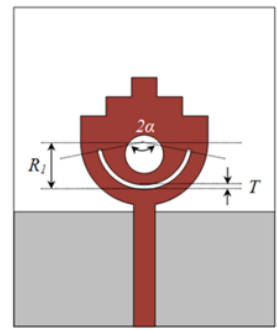

(a)

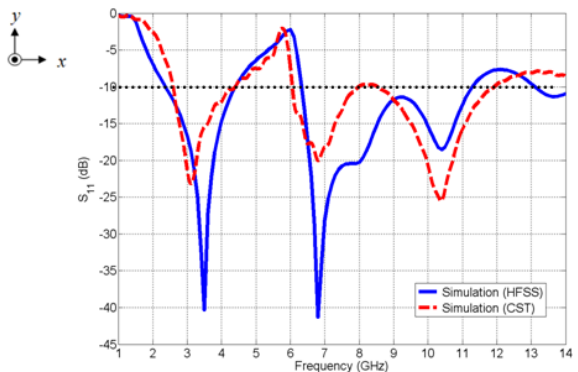

(b)

Figure 14. (a) Geometry of the band-notched antenna, $R 1=7.5 \mathrm{~mm}, \mathrm{~T}=0.7 \mathrm{~mm}$ and $2 \mathrm{a}=160^{\circ}$ (b) Simulated reflection coefficient curves versus frequency.

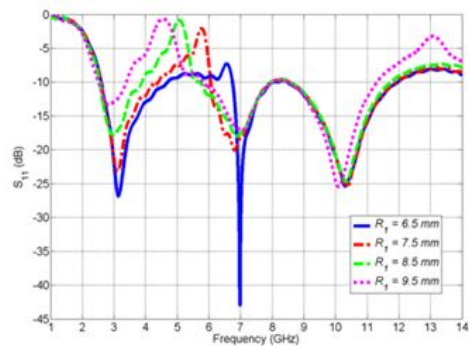

(a)

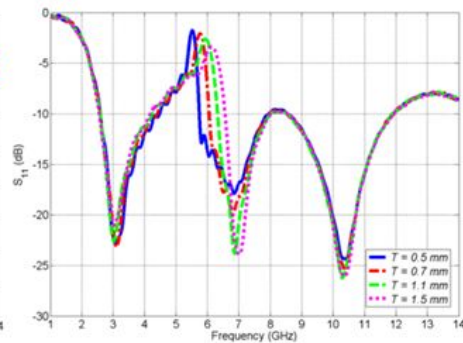

(b)

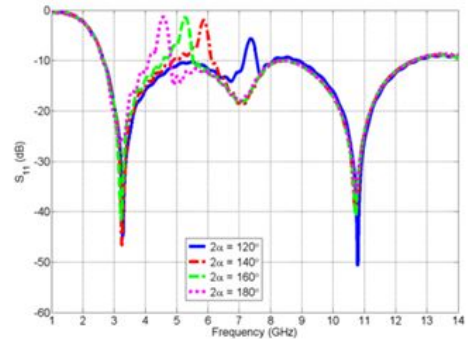

(c)

Figure 15. Simulated reflection coefficient curves versus frequency for different values of (a) arc-shaped slot radius R1, (b) thickness of the slot T and (c) the slot angle $2 a$. 


\subsection{Maple-leaf Shaped Monopole Antennas}

In this section, we developed different maple-leaf shaped monopole antennas with two bandrejection techniques for the 5.0-6.0 GHz frequency band. Fig. 16 (a) \& (b) show the geometrical configuration and the photograph of the proposed UWB maple-leaf-shaped monopole antenna prototype. The radiating element consists of a maple-leaf-shaped patch as a radiating element which represents the Canada flag symbol. The radiat-ing patch is fed by a microstrip line and both are etched on a Rogers RT Duroid 5880 substrate with dielectric constant $\varepsilon \mathrm{r}=2.2$, dielectric loss tangent $\tan \delta=0.0009$, and thickness $\mathrm{h}=1.575 \mathrm{~mm}$. The proposed antenna parameters L1 L10 are determined using an extensive parametric study and optimization in both Ansoft HFSS and CST MWS to address the effect of those parameters on the overall performance of the antenna. Details of the optimized parameters are summarized in Table 1. Our target here is to design a compact antenna for UWB operation. So, we tried to reduce the overall antenna size by reducing the substrate dimensions from $50 \times 41 \mathrm{~mm} 2$ as in the previous antenna design to $35.48 \times 30.56 \mathrm{~mm} 2$ as in the present antenna design. Here, there is a reduction in the an-tenna size by almost $47 \%$ compared to our first proposed antenna prototype, i.e. circular disc monopole antenna with two steps and a circular slot.

\begin{tabular}{lllllllll}
\hline Parameter & W & L & LG & W1 & Wf & d & L1 & L2 \\
\hline Value $(\mathrm{mm})$ & 30.48 & 35.56 & 12.95 & 5.59 & 4.06 & 0.84 & 2.27 & 7.47 \\
\hline Parameter & L3 & L4 & L5 & L6 & L7 & L8 & L9 & L10 \\
\hline Value $(\mathrm{mm})$ & 2.65 & 4.10 & 4.34 & 3.05 & 5.39 & 7.73 & 4.02 & 5.24
\end{tabular}

Table 1. Maple-leaf Shaped Printed Monopole Antenna Dimensions (Units in mm).

The maple-leaf shaped monopole antenna is used to achieve wider impedance matching bandwidth by introducing many leaf arms into the main radiating patch. This will lead to increasing the overall perimeter of the antenna and hence the monopole an-tenna looks bigger in size than its real physical size. This is simply because the current takes paths close to the edges rather than inside the radiating patch. The proposed maple-leaf shaped monopole antenna has a wider bandwidth with smaller size compared to the first UWB antenna design (stepped monopole antenna).

Fig. 17 (a) illustrates the simulated and measured reflection coefficient curves against the frequency for the designed maple-leaf antenna. It can be noticed from the re-sults that the proposed antenna exhibits a simulated impedance bandwidth from 3 to $13 \mathrm{GHz}$ with good agreement between Ansoft HFSS and CST simulation programs while the measured impedance bandwidth becomes dual-band, one in 4.1-7.0 GHz and the other one in 8.7-13.3 GHz. The explanation for the difference between the measured and simulated results can be easily understood if we mention that both simulated reflection coefficient curves are already very close or even touch the $-10 \mathrm{~dB}$ level in the region 7.0-9.0 GHz frequency band. So, if there is any manufacturing error in the antenna parameters L1 L10 during the fabrication proposes of the antenna prototype will be a big issue. This is in addition to calibration errors during S- 
parameters measurement and the effect of SMA connector which was not taken into account during simulations. Also, the manufacturing tolerance as well as the effect of SMA connector has been simulated in CST MWS program and simulation results are shown in Fig. 17 (b) and it is found from the obtained result that it confirms the above explanation.

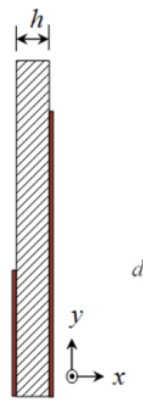

(a)

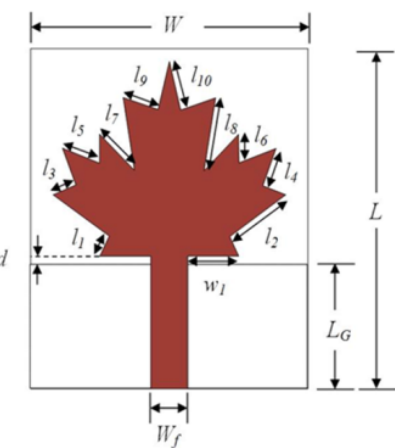

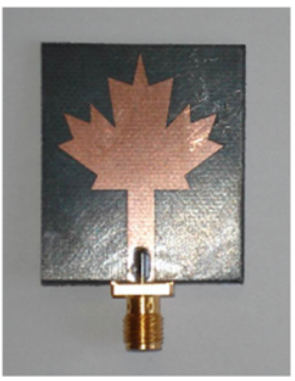

(b)

Figure 16. (a) Geometry and (b) photograph of the proposed maple-leaf shaped printed monopole antenna prototype.

The antenna radiation characteristics across the whole UWB frequency band were also investigated. Fig. 18 shows both the measured and simulated E- and H-plane radiation patterns at frequencies 3, 5, 7, and $9 \mathrm{GHz}$, respectively. The measured H-plane radiation patterns are very close to those obtained in the simulation. It can be noticed that the H-plane patterns are omni-directional at all frequencies of interest. The measured E-plane patterns follow the shapes of the simulated ones, though the agreement is not as good as the H-plane patterns. There are some fluctuations, ripples and distortions on the measured curves, which may be caused by the SMA feed connector and the coaxial cable.

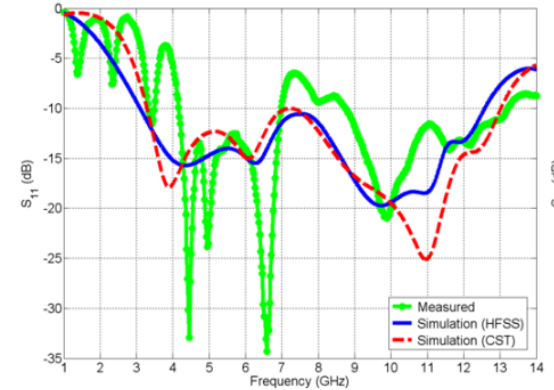

(a)

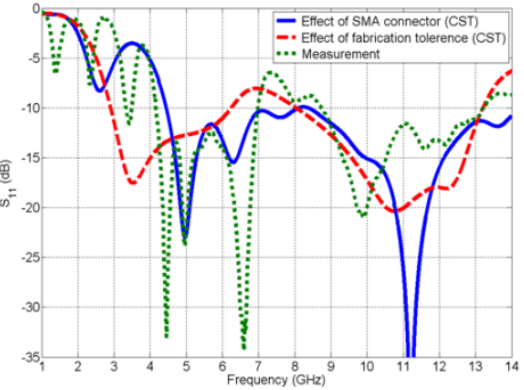

(b)

Figure 17. (a) Measured and simulated reflection coefficient curves of the maple-leaf an-tenna (b) effect of fabrication tolerance on the performance of maple-leaf antenna. 

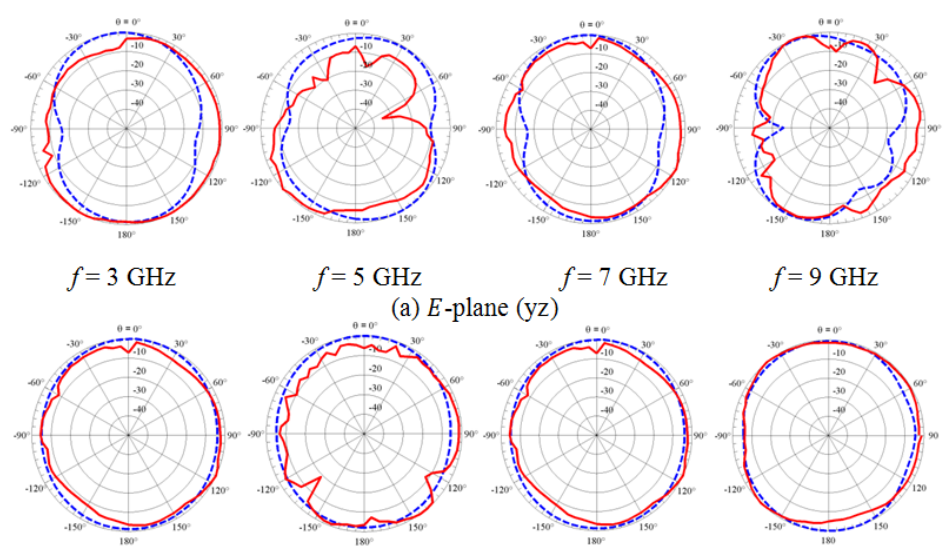

$f=5 \mathrm{GHz}$

(a) E-plane (yz)

$$
f=3 \mathrm{GHz}
$$
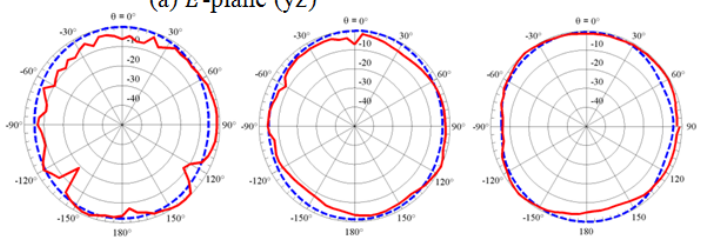

(b) $H$-plane (xz)

$f=7 \mathrm{GHz}$

$f=9 \mathrm{GHz}$

Figure 18. Measured (red solid line) and simulated (blue dashed line) (a) E-plane and (b) H-plane radiation patterns of the maple-leaf antenna.

\subsubsection{Bandstop Antenna Design Prototypes}

We developed two different band-notched antennas using two different tech-niques for band rejection. Fig. 19 (a) introduces the first proposed band-notched anten-na which is designed by modifying the above maple-leaf antenna by cutting a narrow H-shaped slot away from the radiating patch. The $\mathrm{H}$-slot acts as a filtering element where slot dimensions control the rejection band of the band-notched filter. Fig. 19 (b) presents the second proposed band-notched antenna which is designed by cutting two narrow rectangular slits in the ground plane making a DGS. In the maple-leaf band-stop antennas, we achieved VSWR of 10 (reflection coefficient is 0.82 or $-1.7 \mathrm{~dB}$ ) with H-shaped slot and VSWR of 24 (reflection coefficient is 0.92 or $-0.7 \mathrm{~dB}$ ) with two slits in the ground. It can be concluded that using two slits in the ground plane achieves better rejection characteristics compared to using narrow slots (either arc-shaped or $\mathrm{H}$-shaped) in the radiating patch.
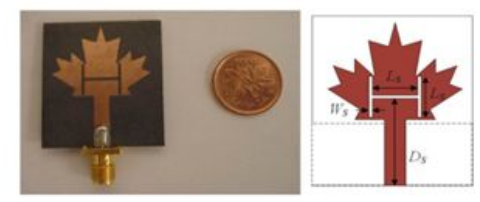

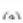
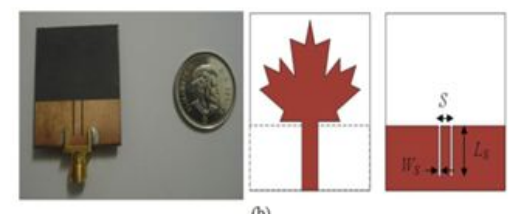

Figure 19. Photograph and geometry of the proposed bandstop antennas using (a) H-slot (b) two slits. 
In both techniques, we can control both the notch center frequency fnotch and the bandwidth BWnotch by adjusting the H-slot and the two slits dimensions, respectively. In the first band-notched antenna, we adjust the slot length LS, thickness WS, and location from the substrate edge DS to control the bandstop characteristic. In the second band-notched antenna, we control the bandstop characteristic by adjusting the two rectangular slits length LS, thickness WS, and distance between them S. The remarkable thing here is that the notch center frequency fnotch is controlled by adjusting the mean length of the slot or the two slits to be about one half-wavelength, i.e. $\lambda / 2$ at the desired notched frequency. For example, the calculated mean length of the H-shaped slot is about $26 \mathrm{~mm}$ and the calculated $\lambda / 2$ at the notch frequency fnotch $=5.5 \mathrm{GHz}$ is $27.7 \mathrm{~mm}$. It is found that the notch bandwidth BWnotch can be controlled by adjusting the thickness of the slot or the two slits.

Fig. 20 (a) \& (b) present the simulated and measured reflection coefficient curves of both band-notched antennas with $\mathrm{H}$-slot (WS $=0.65 \mathrm{~mm}, \mathrm{LS}=8.6 \mathrm{~mm}$ and DS $=18.6 \mathrm{~mm}$ ) and two slits (WS $=0.5 \mathrm{~mm}, \mathrm{LS}=10.2 \mathrm{~mm}$, and $S=3 \mathrm{~mm}$ ), respectively. It is ob-vious from the results that the bandstop function in the $5.0-6.0 \mathrm{GHz}$ is successfully achieved for both antenna designs. The discrepancies in the 7-9 GHz frequency band come from the maple-leaf antenna itself not from the filter elements for band rejection. It can also be noticed that these discrepancies in the 7-9 GHz frequency band are more re-markable in the first prototype than the second one. This is may be due to the effect of using DGS in the finite ground plane enhanced the antenna performance in the $7-9 \mathrm{GHz}$ frequency band.

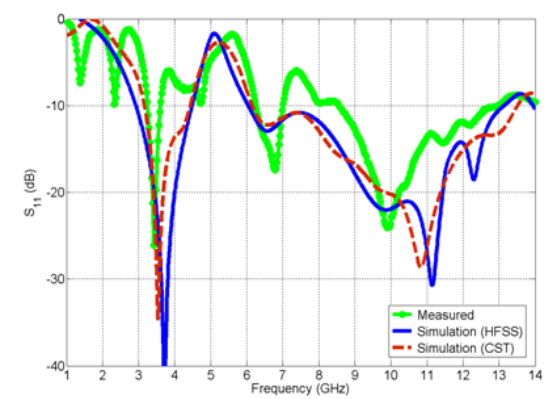

(a)

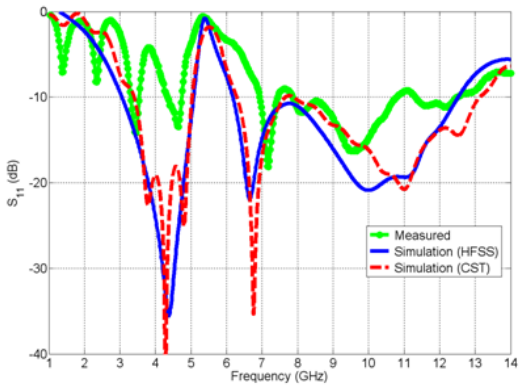

(b)

Figure 20. Measured and simulated reflection coefficient curves for bandstop antennas (a) using an $\mathrm{H}$-slot and (b) using two slits.

Fig. 21 and Fig. 22 show the CST simulated surface current distributions over different frequencies, i.e. 3, 5.5 and $7 \mathrm{GHz}$ for both band-notched antenna designs with H-slot and two slits, respectively. It can be noticed that at the bandstop frequency $5.5 \mathrm{GHz}$, nearly all the currents are trapped at the $\mathrm{H}$-shaped slot or two slits which are preventing the current from radiation while at the radiation frequencies 3 and $7 \mathrm{GHz}$, the current is uniformly distributed through the whole radiating patch. 
The CST simulated antenna maximum realized gains in the bore-sight direction versus frequency for the maple-leaf antenna, band-notched antennas with $\mathrm{H}$-slot and two slits are presented in Fig. 23. It can be seen that the maple-leaf antenna gain is almost stable over the whole frequency band and it ranges from $2 \mathrm{~dB}$ to $4.3 \mathrm{~dB}$ with gain variation about $2.3 \mathrm{~dB}$ through the whole frequency band of interest. For band-notched antenna designs with $\mathrm{H}$ slot and two slits, a sharp gain decrease is remarkably happened in the 5.0-6.0 GHz frequency band. Gain results ensure that the band-notched antennas are not responding in the bandstop frequency range between 5.0 and $6.0 \mathrm{GHz}$.

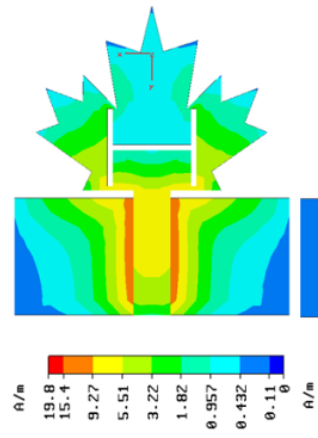

(a)
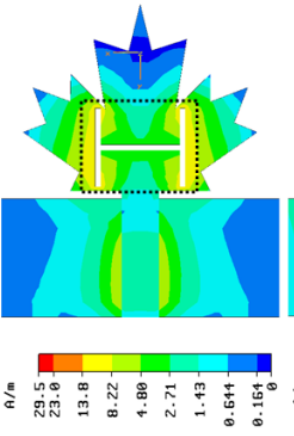

(b)

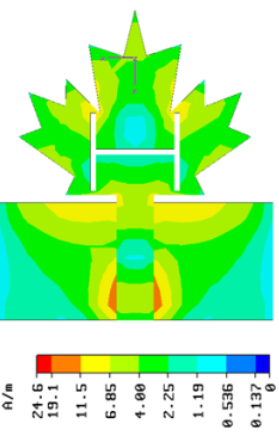

(c)

Figure 21. Current distributions for the first bandstop antenna at the (a) radiating frequency $\mathrm{f} 1=4 \mathrm{GHz}$, (b) bandstop frequency $f 2=5.5 \mathrm{GHz}$ and (c) the radiating frequency $\mathrm{f3}=7 \mathrm{GHz}$.

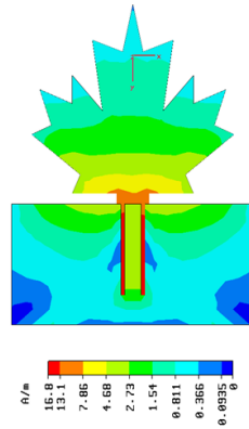

(a)

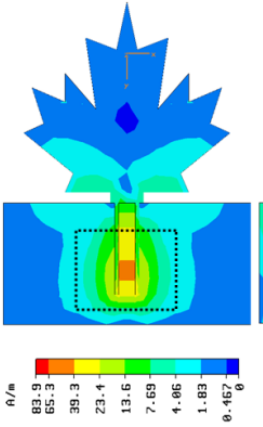

(b)

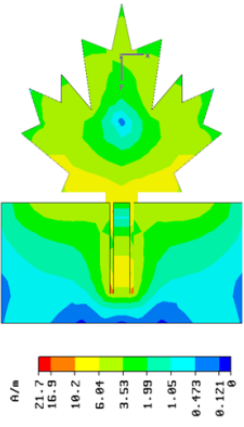

(c)

Figure 22. Current distributions for the second bandstop antenna at the (a) radiating frequency $f 1=4 \mathrm{GHz}$, (b) bandstop frequency $\mathrm{f} 2=5.5 \mathrm{GHz}$ and $(c)$ the radiating frequency $\mathrm{f} 3=7 \mathrm{GHz}$. 


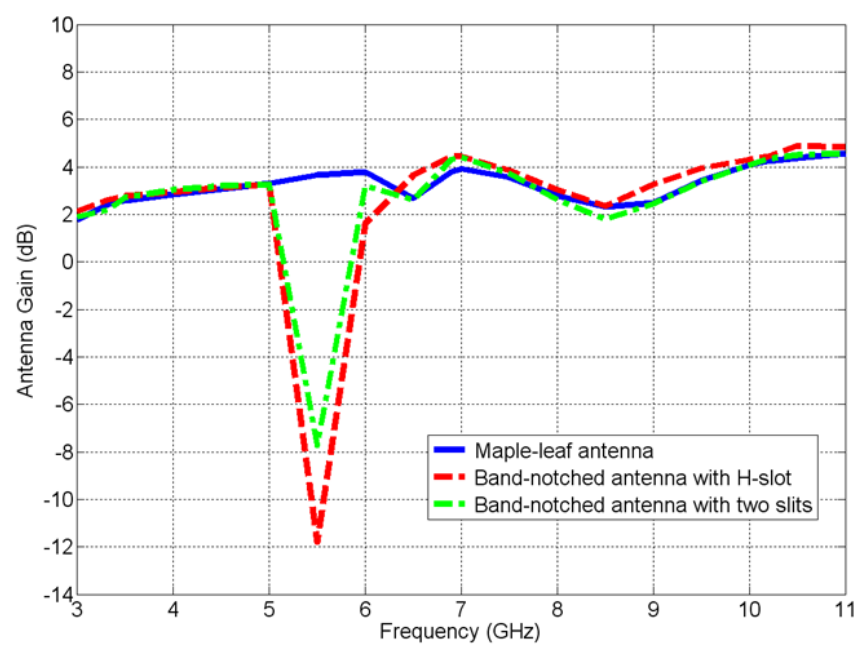

Figure 23. Simulated gain curves versus frequency for all three maple-leaf antennas.

\subsection{Other Shaped Disc Monopole Antennas}

In this section we continue to enhance the UWB antenna performance to obtain a compact in size antenna with maximum possible impedance bandwidth for UWB opera-tion. We are considering the design of two compact omni-directional UWB antennas with different shape of radiating patches. The first design is the butterfly-shaped monopole antenna while the second one is trapezoidal-shaped monopole antenna with a bell-shaped cut as shown in Fig. 24 (a) and (b), respectively. The butterfly-shaped monopole an-tenna size is $35 \times 35 \mathrm{~mm} 2$ which is bigger than the previous maple-leaf-shaped antenna $(35.5 \times 30.5 \mathrm{~mm} 2)$ by about $13 \%$. The other proposed design is the trapezoidal-shaped monopole antenna of size $34 \times 30$ $\mathrm{mm} 2$ which is smaller than the maple-leaf-shaped an-tenna by about $6 \%$. The best candidate among all printed disc monopole antennas from the antenna size point of view is the trapezoidal antenna with bell-shaped cut. Moreover, the candidate antenna still has UWB impedance bandwidth with reasonable stable radia-tion characteristics and constant gain through the desired frequency range.

Both proposed antennas are etched on $1.575 \mathrm{~mm}$-thick Rogers RT 5880 substrate and fed by $50 \Omega$ characteristic impedance microstrip line. The finite ground plane length is $L G=10 \mathrm{~mm}$ and the feed gap width is $\mathrm{d}=0.5 \mathrm{~mm}$. The butterfly-shaped antenna consists of a radiating element of two overlapped elliptical discs of major radius $\mathrm{a}=16.6 \mathrm{~mm}$ and a minor radius $\mathrm{b}$ $=10.4 \mathrm{~mm}$ (elliptically ratio $\mathrm{a} / \mathrm{b} \approx 1.6$ forming the two wings of the butterfly). Two annular slot rings of an outer radius $\mathrm{r} 1=2 \mathrm{~mm}$ and an inner radius $\mathrm{r} 2=1 \mathrm{~mm}$ have been cut out from the radiating patch. They are located at distance c $(=\mathrm{e})=5.2 \mathrm{~mm}$ from the two ellipses' edges. These slot rings can increase the bandwidth of the proposed antenna and they are useful to reduce the overall metallic area. 

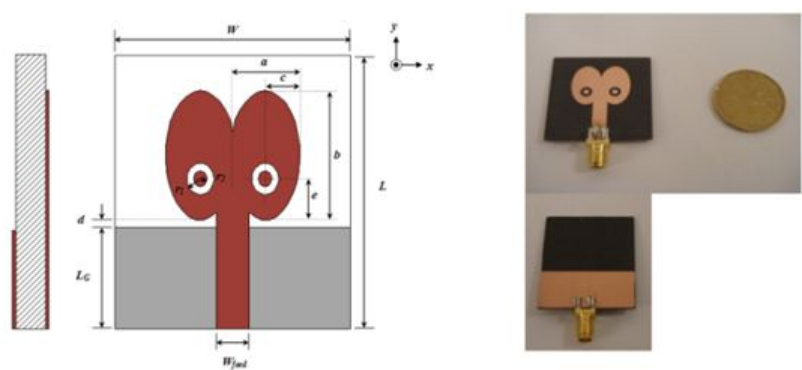

(a)
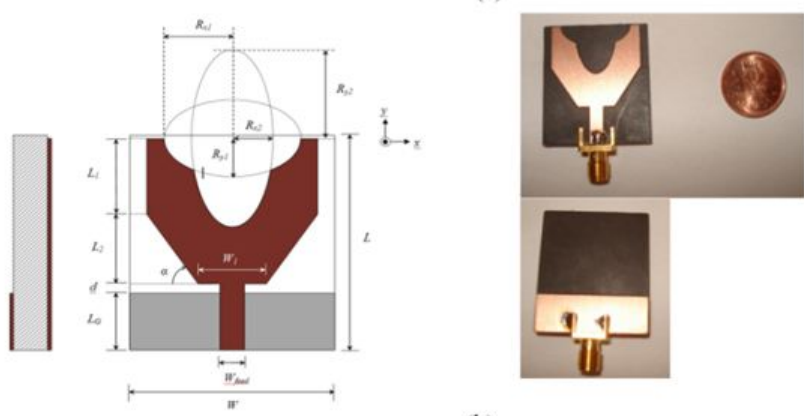

(b)

Figure 24. Geometry and photograph of the (a) butterfly-shaped (b) trapezoidal-shaped monopole antenna.

The trapezoidal-shaped antenna consists of a trapezoidal patch of dimensions L1 $=12 \mathrm{~mm}$, $\mathrm{L} 2=11 \mathrm{~mm}, \mathrm{~W} 1=10 \mathrm{~mm}$ and bevel angle $\alpha=55.7^{\circ}$. Two elliptical cuts have been cut out from the radiating patch forming a bell shaped cut. The first elliptical cut is of a major radius $\mathrm{Rx} 1=10 \mathrm{~mm}$ and a minor radius $\mathrm{Ry} 1=6 \mathrm{~mm}$ (elliptically ratio $\mathrm{Rx} 1 / \mathrm{Ry} 1=1.67$ ). The second elliptical cut is of a minor radius $\mathrm{Rx} 2=6 \mathrm{~mm}$ and a major radius Ry2 $=14 \mathrm{~mm}$ (elliptically ratio $R y 2 / R x 2=2.33$ ). An antenna prototype of both structures with optimized parameters has been fabricated for experimental investigation.

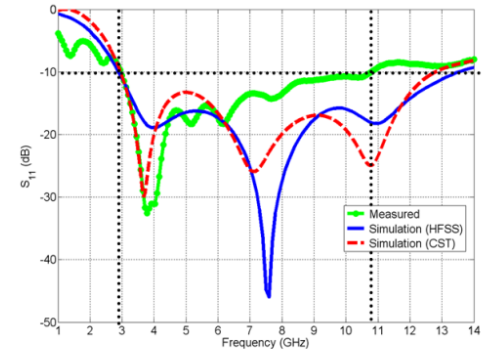

(a)

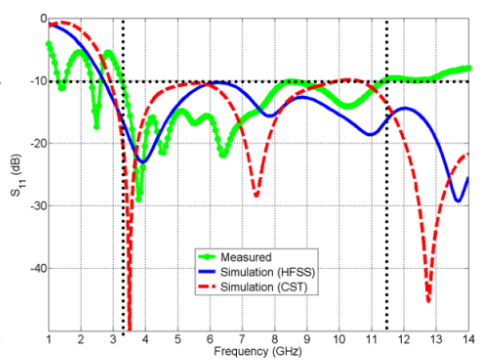

(b)

Figure 25. Measured and simulated reflection coefficient curves of the (a) butterfly antenna and (b) trapezoidal antenna. 
The measured and simulated reflection coefficient curves against frequency for butterfly and trapezoidal antennas are plotted in Fig. 25, respectively. It is observed from the results that the simulated reflection coefficient with Ansoft HFSS and CST are almost in good agreement and both antennas exhibit wide impedance bandwidth from $3 \mathrm{GHz}$ to beyond $12 \mathrm{GHz}$ (FBW is > $110 \%$ ) for both antennas. The measured results shows that the both antenna designs still have wide impedance bandwidth covering the UWB frequency range. It is shown that there are different resonances occur at different frequencies across the UWB frequency range and the overlap among these resonances achieve the wide bandwidth characteristic of those types of printed monopole antenna. The measured and simulated E- and $\mathrm{H}$-plane radiation patterns at frequencies 3, 5, 7 and $9 \mathrm{GHz}$ are illustrated in Fig. 26 and Fig. 27, respectively. As expected, both antennas exhibit a dipole-like radiation patterns in E-plane and good omni-directional radiation patterns in $\mathrm{H}$-plane.
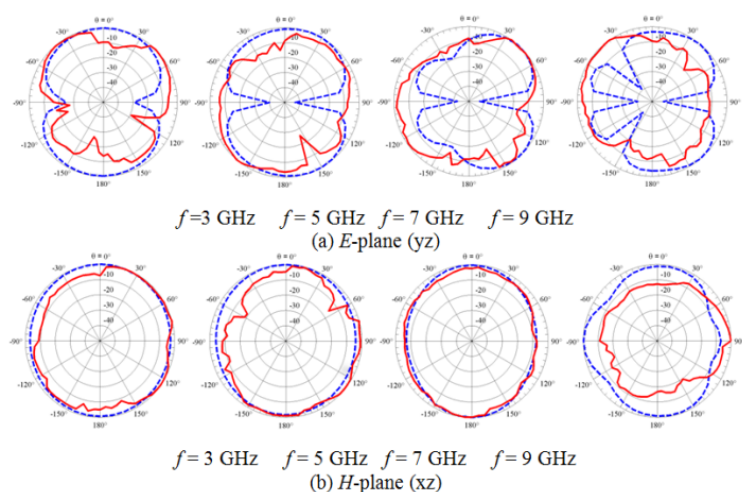

Figure 26. Measured (red solid) and simulated (blue dashed) (a) E-plane and (b) H-plane radiation patterns for butterfly antenna.
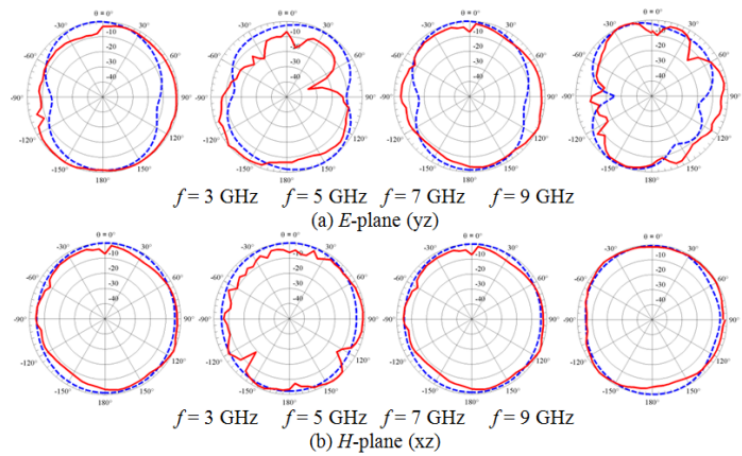

Figure 27. E- and H-plane radiation patterns of the trapezoidal antenna. Blue dashed lines for simulated and red solid lines for measured. 
Both physical and electrical properties of different UWB disc monopole antennas for shortrange wireless communications are summarized in Table 2. The comparison includes the overall antennas dimensions, $10 \mathrm{~dB}$ return loss bandwidth, realized gain and groub delay features. It can be seen that the Trapezoidal monopole antenna with bell-shaped cut is the good candidate among all proposed antenna designs in terms of both physical and electrical propoerties.

\begin{tabular}{|c|c|c|c|c|}
\hline Parameter & $\begin{array}{l}\text { Circular disc } \\
\text { monopole with two } \\
\text { steps and a circular } \\
\text { slot }\end{array}$ & Maple-leaf antenna & Butterfly antenna & $\begin{array}{l}\text { Trapezoidal antenna } \\
\text { with bell-shaped cut }\end{array}$ \\
\hline Dimensions (mm) & $41 \times 50 \times 1.575$ & $30.5 \times 35.5 \times 1.575$ & $35 \times 35 \times 1.575$ & $30 \times 34 \times 1.575$ \\
\hline $\begin{array}{l}10 \mathrm{~dB} \text { RL bandwidth } \\
(\mathrm{GHz})\end{array}$ & $3.0 \sim 11.5$ & $\begin{array}{l}\text { 4.1 7.0, 8.7 13.3 } \\
\text { (Dual-band) }\end{array}$ & $3.0 \sim 10.8$ & $3.2 \sim 11.4$ \\
\hline $\begin{array}{l}10 \mathrm{~dB} \text { RL bandwidth } \\
(\%)\end{array}$ & $117 \%$ & $52 \%, 42 \%$ & $113 \%$ & $112 \%$ \\
\hline Realized gain (dB) & $\begin{array}{l}3.4 \sim 5.2 \\
\pm 1.8\end{array}$ & $\begin{array}{l}2.0 \sim 4.3 \\
\pm 2.3\end{array}$ & $\begin{array}{l}2.0 \sim 4.7 \\
\pm 2.7\end{array}$ & $\begin{array}{l}2.7 \sim 5.3 \\
\pm 2.6\end{array}$ \\
\hline Group delay (ns) & 4.2 & 2.7 & 1.5 & 4.2 \\
\hline
\end{tabular}

Table 2. Comparison among Different UWB Antenna Design Prototypes.

\subsection{Transmission Characteristics of UWB Antennas}

In this section, we investigate the transmission/reception $(\mathrm{Tx} / \mathrm{Rx})$ characteristics of different UWB antennas discussed above in both time and frequency domains. We set up various scenarios and study the communication link between two identical prototype an-tennas. The distance between the transmitting and receiving antennas is assumed to be $30 \mathrm{~cm}$ which is approximately 3 wavelengths at the lower frequency of the considered band of operation (antennas are in the far field of each other). Two different scenarios are established for our study. The first one is the face-to-face scenario where the two identic-al antennas are placed in vertical position facing each other at a separation distance be-tween the two antennas of $d$ as shown in Fig. 28(a). The second case is the end-to-end scenario where the two antennas are placed in horizontal position facing each other at a separation distance $d$ as shown in Fig. 28(b). This study is carried out calculated in the E-plane $\left(\phi=90^{\circ}\right)$ at different observation angles $\theta$. 


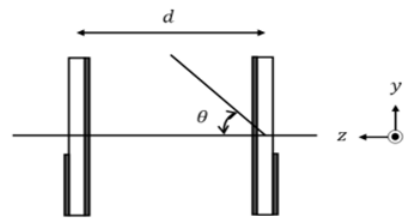

(a)

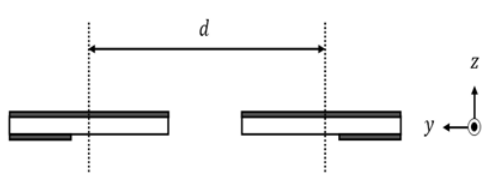

(b)

Figure 28. Configuration of UWB transmission system in case of (a) face-to-face scenario and (b) end-to-end scenario.

\subsubsection{Time-Domain Characteristics}

For a complete description of the antenna characteristics, the time domain behavior is calculated in the E-plane $\left(\phi=90^{\circ}\right)$ at different observation angles: $\theta=0^{\circ}, 30^{\circ}, 60^{\circ}, 90^{\circ}$. Referring to Fig. 29(a), the incident wave arriving at the receiving antenna is assumed to be the fourth derivative of a Gaussian function

$$
s_{i}(t)=A\left(3-6\left(\frac{4 \pi}{\tau^{2}}\right) t^{2}+\left(\frac{4 \pi}{\tau^{2}}\right)^{2} t^{4}\right) \cdot e^{-2 \pi\left(\frac{t}{\tau}\right)^{2}}(\mathrm{~V} / \mathrm{m})
$$

where $\mathrm{A}=0.1$ and $\tau=0.175$ ns. The normalized spectrum of this pulse is illustrated in Fig. 29(b), and proves to comply with the required FCC indoor emission mask. Further refining the pulse spectrum can be achieved by utilizing some optimization algorithms. The pulse spectrum is then multiplied by the normalized antenna transfer functions and an inverse Fourier transform (IFT) is performed to achieve the required time domain response. The output waveform at the receiving antenna terminal can therefore be expressed by where represents an ideal bandpass filter from 1 to $18 \mathrm{GHz}$.

Fig. 30 presents the CST Simulated radiation waveforms in the E-plane at different angles $\theta$ $=0^{\circ}, 30^{\circ}, 60^{\circ}, 90^{\circ}$ in face-to-face scenario for different UWB antenna prototypes.

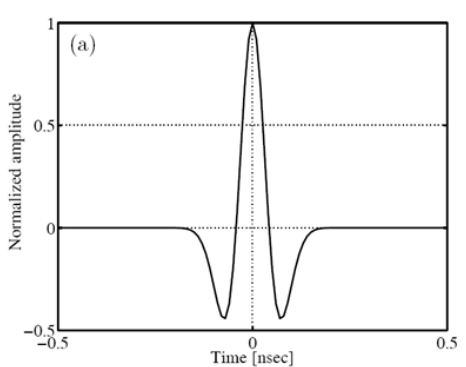

(a)

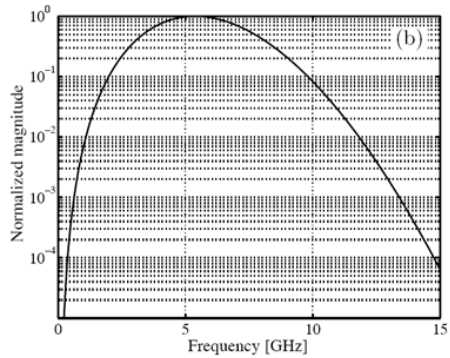

(b)

Figure 29. (a) Received UWB pulse shape and (b) spectrum of a single received UWB pulse [35]. 


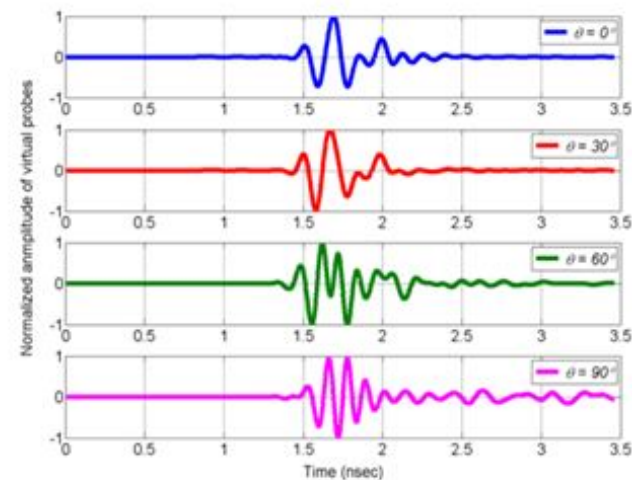

(a)

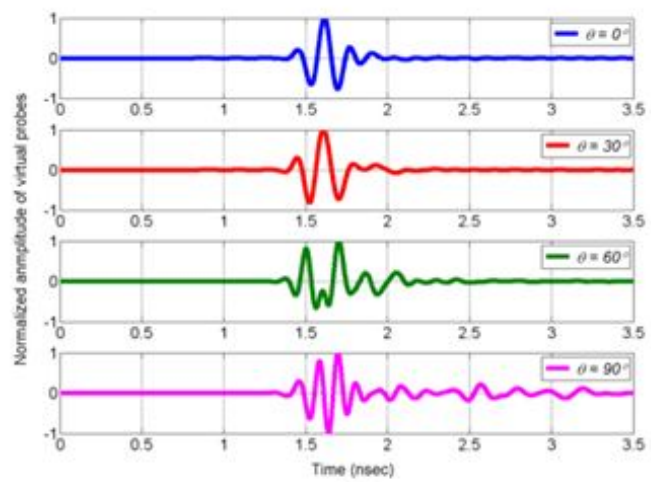

(c)

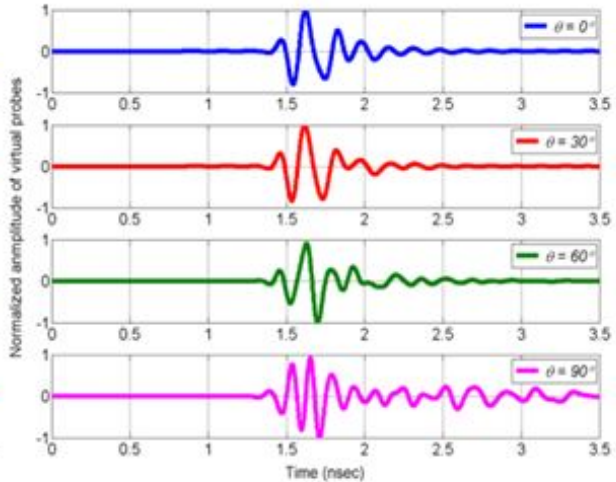

(b)

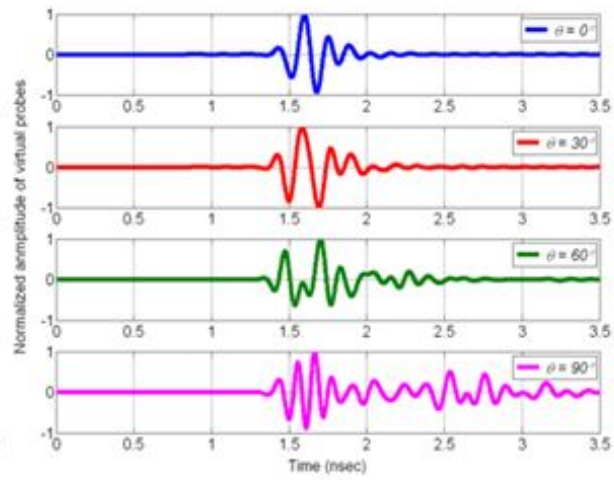

(d)

Figure 30. CST Simulated radiation waveforms in the E-plane at different angles $\theta=0^{\circ}, 30^{\circ}, 60^{\circ}, 90^{\circ}$ in face-to-face scenario for (a) circular disc with two steps and a circular slot antenna (b) maple-leaf monopole antenna (c) butterfly monopole antenna (d) trapezoidal monopole antenna.

\subsubsection{Frequency-Domain Characteristics}

Since virtual probes are situated in the E-plane $\left(\phi=90^{\circ}\right)$, we expect the Tx/Rx system frequency-domain transfer function in face-to-face scenario to become more flat than end-toend scenario. The separation distance between two transmit and receive antennas is set to d $=30 \mathrm{~cm}$. The simulated impulse responses for both scenarios are given in Fig. 31(a) and (b), respectively. It is shown the ringing effect is slightly less in the face-to-face case compared to the end-to-end case. Fig. 32 shows the simulated transmission coefficients IS21 I against frequency at different angles $\theta=0^{\circ}, 30^{\circ}, 60^{\circ}, 90^{\circ}$ in face-to-face scenario for different UWB antenna prototypes. 


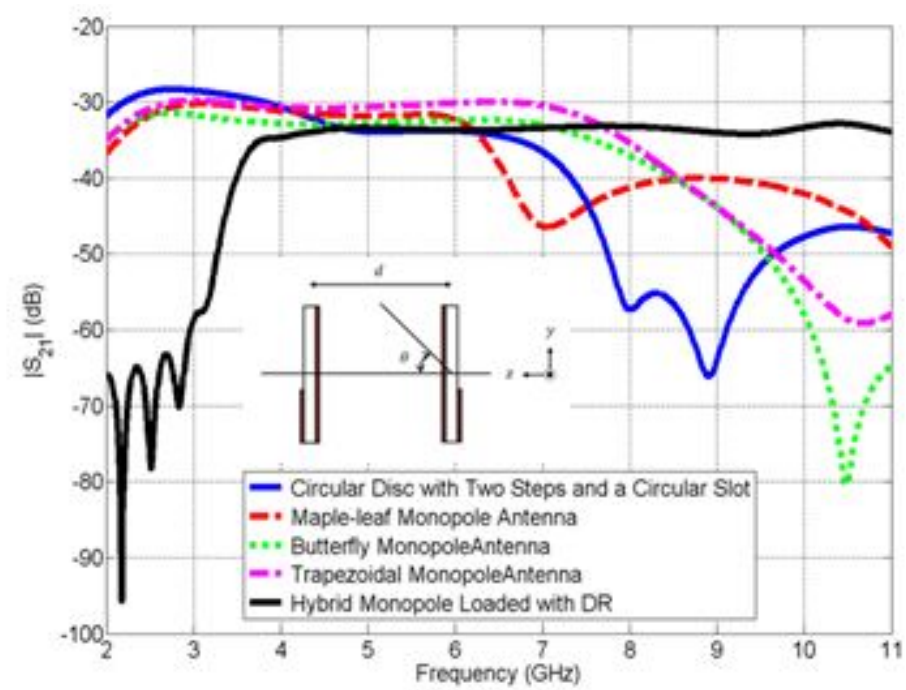

(a)

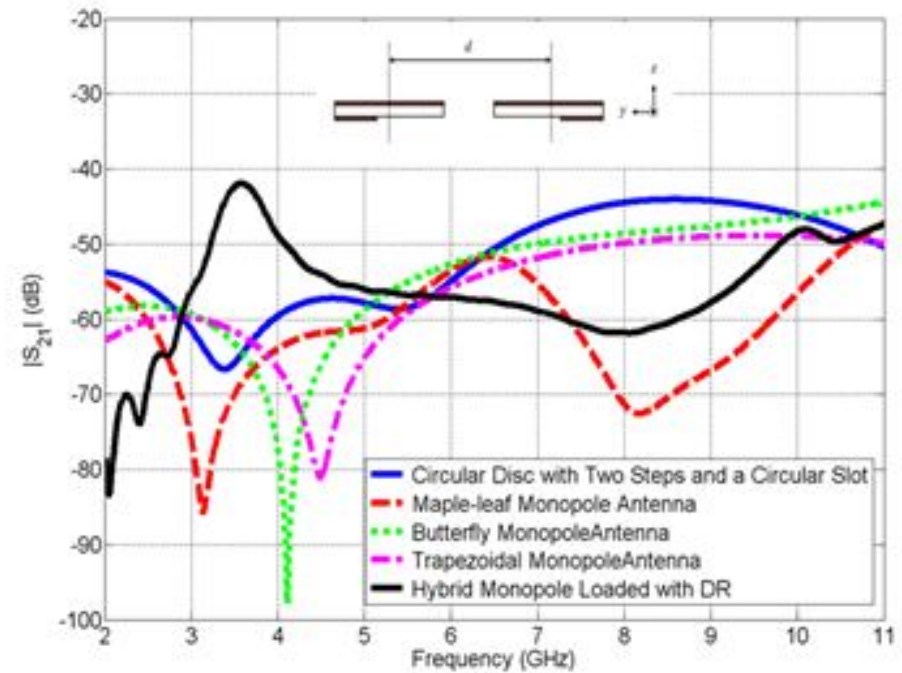

(b)

Figure 31. CST Simulated transmission coefficients $|S 21|$ as a function of frequency for different UWB antennas in case of (a) face-to-face scenario (b) end-to-end scenario. 


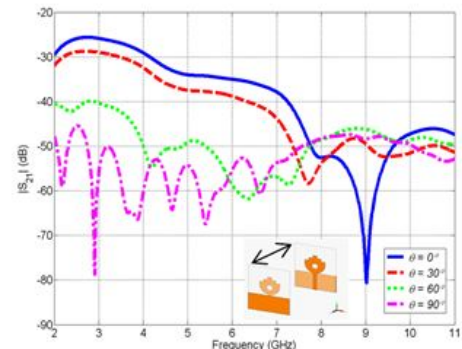

(a)

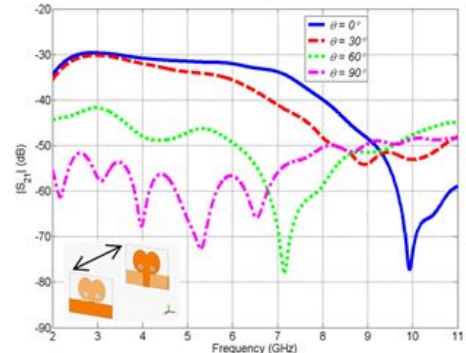

(c)

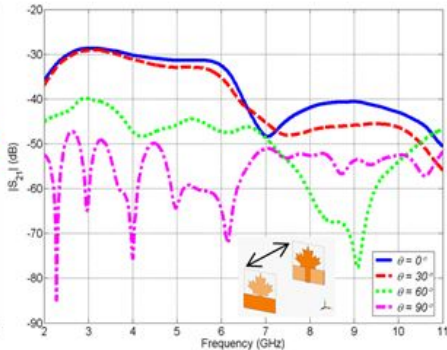

(b)

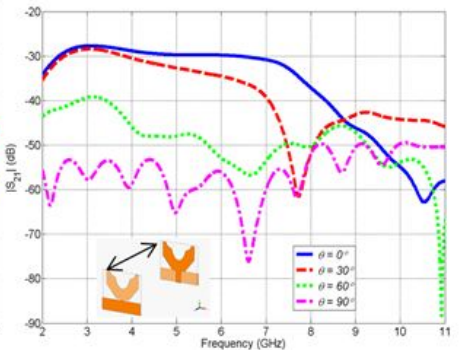

(d)

Figure 32. CST Simulated transmission coefficients $|S 21|$ as function of frequency at different angles $\theta=0^{\circ}, 30^{\circ}, 60^{\circ}$, $90^{\circ}$ in face-to-face scenario for (a) circular disc with two steps and a circular slot antenna (b) maple-leaf monopole antenna (c) butterfly monopole antenna (d) trapezoidal monopole antenna.

\section{Summary}

In this chapter, different UWB disc monopole antennas have been developed in microstrip PCB technology to achieve low profile and ease of integration. Parametric studies to see the effect of some antenna parameters on its performance have been numer-ically investigated. For further understanding the behavior of the proposed antennas, sur-face current distributions have been simulated and presented. Different techniques for obtaining bandstop function in the 5.0-6.0 GHz frequency band to avoid interference with other existing WLAN systems have been numerically and experimentally presented. The effects of band-notched parameters on the band-notch frequency and bandwidth have been studied. The chapter has investigated the frequency domain performances of different printed disc monopole antennas and hybrid antenna. Experimental as well as the simulated results have confirmed UWB characteristics of the proposed antennas with nearly stable omni-directional radiation properties over the entire frequency band of interest. These features and their small sizes make them attractive for future UWB applications. 


\section{Acknowledgements}

This research is partially supported by the King Saud University - National Plan for Sciences and Technology (NPST) through Research Grant 09ELE858-02 and by KACST Technology Innovation Center in RFTONICS hosted by King Saud University.

\section{Author details}

Osama Haraz ${ }^{1 *}$ and Abdel-Razik Sebak ${ }^{1,2^{*}}$

*Address all correspondence to: osama_m_h@yahoo.com

1 Electrical and Computer Engineering Department, Concordia University, Canada

2 KACST Technology Innovation Center in RFTONICS, PSATRI, King Saud University, Saudi Arabia

\section{References}

[1] FCC. (2002). First report and order, revision of part 15 of the commission's rules regarding ultra-wideband transmission systems FCC.

[2] di Benedetto, M. G., Kaiser, T., Molisch, A. F., Oppermann, I., Politano, C., \& Por-cino, D. (2006). UWB Communications Systems: A Comprehensive Overview: Hindawi.

[3] Linardou, I., Migliaccio, C., Laheurte, J. M., \& Papiernik, A. (1997). Twin Vivaldi antenna fed by coplanar waveguide. Electron. Lett., 33(22), 1835-1837.

[4] Kim, S. G., \& Chang, K. (2004). Ultra Wideband Exponentially-Tapered Antipodal Vivaldi Antennas. IEEE Antennas and Propagation Society Symposium, Monterey, CA, June, 3, 2273-2276.

[5] Sibille, A. (2005). Compared Performance of UWB Antennas for Time and Frequency Domain Modulation. 28th URSI General Assembly, NewDelhi, India.

[6] Licul, S, Noronha, J. A. N., Davis, W. A., Sweeney, D. G., Anderson, C. R., \& Bielawa, T. M. (2003). A parametric study of time-domain characteristics of possible UWB antenna architectures. IEEE 58th Vehicular Technology Conference, VTC 2003-Fall, October, 5, 6-9.

[7] Sego, D. J. (1994). Ultrawide Band Active Radar Array Antenna for Unmanned Air Vehicles. Proc. IEEE Nat. Telesyst. Conf., 13-17. 
[8] Su, S. W., Wong, K. L., \& Tang, C. L. (2004). Ultra-wideband square planar monopole antenna for IEEE 802.16a operation in the 2-11 GHz band. Microwave Opt. Tech-nol. Lett., 42(6), 463-466, Sept.

[9] Chen, Z. N., Ammann, M. J., \& Chia, M. Y. W. (2003). Broadband square annular planar monopoles. Microwave Opt. Technol. Lett., 36(6), 449-454, Mar.

[10] Chen, Z. N., Ammann, M. J., Chia, M. Y. W., \& See, T. S. P. (2002). Annular planar mono-pole antennas. IEE Proc. Microw. Antennas Propag., 149(4), 200-203, Aug.

[11] Ahmed, O. M., Elboushi, A., \& Sebak, A. R. (2012). Design of Half Elliptical Ring Monopole Antennas with Elliptical Slot in Ground Plane for Future UWB Applications, Microwave and Optical Technology Letters, 54(1), 181-187, January.

[12] Ahmed, O. M. H., \& Sebak, A. R. (2011). A Novel Printed Monopole Antenna for Future Ultrawideband Communication Systems. Microwave and Optical Technology Letters August, 53(8), 1837-1841.

[13] Osama, M. H. Ahmed, \& Sebak, Abdel-Razik. (2010). Planar Ultrawideband Antenna Array for Short-Range Wireless Communications. Microwave and Optical Technology Letters, 52(5), 1061-1066, Mar.

[14] Azenui, N. C., \& Yang, H. Y. D. (2007). A printed crescent patch antenna for ultrawideband applications. IEEE Antennas Wireless Propag. Lett., 6, 113-116.

[15] Ahmed, O., \& Sebak, A. R. (2008). A Printed Monopole Antenna with Two Steps and a Circular Slot for UWB Applications. IEEE Antennas Wireless Propag. Lett., 7, 411-413.

[16] Hsu, C. H. (2007). Planar multilateral disc monopole antenna for UWB application. Microwave Opt. Technol. Lett., 49(5), 1101-1103, May.

[17] Chen, Z. N., Ammann, M. J., Chia, M. Y. W., \& See, T. S. P. (2002). Annular planar monopole antennas. IEE Proc. Microw. Antennas Propag, 149(4), 200-203, Aug.

[18] Huang, C. Y., \& Hsia, W. C. (2005). Planar elliptical antenna for ultra-wideband communications. Electron. Lett., 41(6), 296-297, Mar.

[19] Liang, J., Chiau, C. C., Chen, X., \& Parini, C. G. (2005). Study of a printed circular disc monopole antenna for UWB systems. IEEE Trans. Antennas Propag., 53(11), 3500-3504, Nov.

[20] Xuan Hui, Wu, \& Ahmed, A. Kishk. (2008). Study of an Ultrawideband Omnidirectional Rolled Monopole Antenna With Trapezoidal Cuts. IEEE Transactions on Antennas and Propagations, 56(1), 259-263, Jan.

[21] Ahmed, O. M. H., \& Sebak, A. R. (2011). Numerical and Experimental Investigation of a Novel Ultrawideband Butterfly Shaped Printed Monopole Antenna with Bandstop Function. Progress In Electromagnetics Research PIER C, 18, 111-121. 
[22] Liu, H. W., Ku, C. H., Wang, T. S., \& Yang, C. F. (2010). Compact monopole antenna with band-notched characteristic for UWB applications. IEEE Antennas Wireless Propag. Lett., 9, 397-400.

[23] Elboushi, A., Ahmed, O. M., \& Sebak, A. R. (2010). Study of Elliptical Slot UWB Antennas with A 5.0-6.0GHz Band-Notch Capability. Progress In Electromagnetics Research PIER C, 16, 207-222.

[24] Osama, M. H. Ahmed, \& Abdel-Razik, Sebak. (2009). A Novel Maple-Leaf Shaped UWB Antenna with a 5.0-6.0 GHz Band-Notch Characteristic. Progress In Electromagnetics Research PIER C, , 11, 39-49.

[25] Ojaroudi, M., Ghanbari, G., Ojaroudi, N., \& Ghobadi, C. (2009). Small square monopole antenna for UWB applications with Variable frequency band-notch function. IEEE Antennas Wireless Propag. Lett., 8, 1061-1064.

[26] Ahamadi, B., \& Dana, R. F. (2009). A miniaturized monopole antenna for ultrawideband applications with band-notch filter. IET Microwave antennas Propagations, 3, 1224-1231.

[27] Huang, C. Y., Huang, S. A., \& Yang, C. F. (2008). Band-Notched Ultra-Wideband Circular Slot Antenna with Inverted C-Shaped Parasitic Strip. July. Electron. Lett., 44(15), 891-892.

[28] Kenny, S. Ryu, \& Ahmed, A. Kishk. (2009). UWB Antenna with Single or Dual Bandnotches for Lower WLAN Band and Upper WLAN Band. IEEE Transactions on Antennas and Propagations, 57(12), 3942-3950, DEC.

[29] Constantine, A. Balanis. (2005). Antenna Theory Analysis and Design. by John Wiley \& Sons, INC.

[30] Liang, J. (2006). Antenna Study and Design for Ultra Wideband Communication Applications. PhD Thesis, July.

[31] Yan, X. R., Zhong, S. S., \& Wang, G. Y. (2007). Compact Printed Monopole Antenna with 24:1 Impedance Bandwidth. Microwave Opt. Tech. Lett., 49(11), 2883-2886.

[32] Yan, X. R., Zhong, S. S., \& Liang, X. L. (2007). Compact printed semi-elliptical monopole antenna for super-wideband applications. Microwave Opt. Tech. Lett., 49, 2061-2063.

[33] Low, Z. N., Cheong, J. H., \& Law, C. L. (2005). Low-cost PCB antenna for UWB applications. IEEE Antennas Wireless Propag Lett, 4, 237-239.

[34] Choi, S. H., Park, J. K., Kim, S. K., \& Park, J. Y. (2004). A new ultrawideband antenna for UWB applications. Microwave Opt. Tech. Lett., 40(5), Mar.

[35] Ghavami, M., Michael, L., \& Kohno, R. (2004). Ultra Wideband Signals and Systems in Communication Engineering. John Wiley \& Sons. 